\title{
Origin of prostaglandins in human semen
}

\author{
K. Gerozissis, P. Jouannet*, J. C. Soufir* and F. Dray
}

INSERM U 207 -Institut Pasteur, U.R.I.A., 28 rue du Dr Roux, 75724 Paris Cedex 15, France and ${ }^{*}$ Laboratoire Histologie Embryologie, Centre Hospitalier de Bicêtre, 78 rue du Général Leclerc, 94270 Kremlin Bicêtre, France

\begin{abstract}
Summary. The prostaglandins, PGE-1, PGE-2, PGF-1 $\alpha$, PGF-2 $\alpha, 19-$ OH-PGE$(1+2), 19-O H-P G F-\alpha$ were estimated by RIA in the semen of (a) normal men of proven fertility (total semen or split ejaculate); (b) men 1 year after vasectomy; and (c) men with agenesia of the vas deferens and seminal vesicles. PG concentrations in the semen of vasectomized men were largely within the normal ranges. In men with agenesia of the vas deferens and seminal vesicles, PG concentrations were $10^{2}-10^{5}$-fold less than that measured in normal subjects. The patterns of $19-\mathrm{OH}-\mathrm{PGs}$ and PGF- $\alpha$ in the five fractions of a split ejaculate followed in general the fructose profile. These data suggest that prostaglandins mostly originate in the seminal vesicles.
\end{abstract}

\section{Introduction}

Although it is generally believed that prostaglandins (PGs) present in human semen are secreted by the seminal vesicles, as has been shown in the ram, the experimental proof has not yet been obtained, not even for PGE-2 and PGF-2 $\alpha$, which have been identified for some time (Eliasson, 1959; Cenedella, 1975; Fuchs \& Chantharaksri, 1976). There is, in fact, only limited direct evidence for the synthesis of human seminal PGs by the seminal vesicles (Eliasson, 1959; Bygdeman \& Eliasson, 1969; Hamberg, 1976). Moreover, the 19-hydroxylated PGs, and not the prostanoic derivatives studied previously (PGE, PGF or 19-OH-PGA, PGB), are the major prostaglandins in the human semen (Taylor \& Kelly, 1974; Templeton, Cooper \& Kelly, 1978). A correlation between fructose and 19-hydroxy-PGE levels in human seminal plasma suggests that these PGs are secreted by the seminal vesicles (Conte, Laguzzi, Gioveno, Dondero \& Isidori, 1979). The present study was undertaken to attempt clarification of the origin of prostaglandins in human semen.

\section{Materials and Methods}

\section{Materials}

All unlabelled PGs were a gift from Dr J. Pike (UpJohn Company, Kalamazoo, Michigan, U.S.A.). Tritium-labelled PGs were used for the PGE-1, PGE-2, PGF- $1 \alpha$ and PGF-2 $\alpha$ assays. The iodinated tracers for 19-OH-PGE-2, 19-OH-PGF- $\alpha$, and the antisera for all the PG radioimmunoassays, were prepared as previously described (Maclouf, Pradel, Pradelles \& Dray, 1976; Gerozissis \& Dray, 1981).

The semen of selected groups of men was analysed. 
Men with proven fertility. The fertility of these men was checked by two criteria, i.e. paternity within the past 10 years and normal spermiogram values (ejaculate volume 2-6 ml, $>20 \times 10^{6}$ spermatozoa $/ \mathrm{ml}$, sperm motility $\geqslant 50 \%$ ). Samples with normal spermiogram values were also used from students without children; these ejaculates were collected in 5 fractions (Eliasson \& Lindholmer, 1976).

Vasectomized men. These men had children $<10$ years of age and normal spermiogram values before operation. The semen was collected 1 year after vasectomy and was free from spermatozoa.

Men with an obstructive sterility (ejaculatory duct and seminal vesicle agenesia). The lack of patency of the vas deferens was suggested by an azoospermia accompanied by an absence of seminal fructose and an elevated acid phosphatase; it was confirmed by clinical examination and surgery. All the men were asked to abstain from coitus for 3 days before collection of the samples by masturbation within $5 \mathrm{~min}$ of ejaculation. Part $(0.1 \mathrm{ml})$ of each sample was placed in liquid nitrogen and stored until assayed for prostaglandins. Another part of the semen samples was allowed to stand for $30 \mathrm{~min}$ after collection at room temperature $\left(20-25^{\circ} \mathrm{C}\right)$ for liquefaction and then tested for quality (volume, number of spermatozoa, sperm motility).

\section{Assays}

The prostaglandins were measured by radioimmunoassay. The samples were diluted to $1 / 10$ with 0.1 M-potassium phosphate buffer, $\mathrm{pH} 7.4$, containing $0.02 \%$ aspirin, $0.1 \%$ glucose and $0.9 \%(\mathrm{w} / \mathrm{v}) \mathrm{NaCl}$, acidified to $\mathrm{pH} 4$ and extracted twice with ethyl acetate. After extraction, the prostaglandins were purified by silicic acid column chromatography (Gerozissis \& Dray, 1977, 1981).

The assay methods and the binding characteristics of the antisera to prostaglandins, were as reported previously (Dray, Charbonnel \& Maclouf, 1975; Dray et al.,1980; Gerozissis \& Dray, 1981). The assays of each of the substances measured were validated by the following tests; non-specific binding (blank, $90 \pm 10 \%)$, recovery of known amounts of each PG $(>80 \%)$; the coefficient of variation between and within assays (6-10\%). The non-specific binding and the recovery of tritiated PGE-2, PGF- $2 \alpha(\sim 1500$ d.p.m. added before acidification) were checked for all dosages. The sensitivities of the assays (quantity of $P G$ in $\mathrm{pg}$ to give $50 \%$ displacement of $\mathrm{B}_{0}$ ) were 5 for PGE-2, 10 for PGF-2 $\alpha, 15$ for PGF-1 $\alpha$ and 19-OH-PGE(1 + 2), 32 for PGE-1 and 150 for 19-OH-PGF- $\alpha$.

L(-)-Carnitine and fructose determinations, after thawing of samples, took place in 3 steps, i.e. $20 \mathrm{~min}$ at $-20^{\circ} \mathrm{C}, 30 \mathrm{~min}$ at $+4^{\circ} \mathrm{C}$ and then exposure to room temperature. The separation of spermatozoa and seminal plasma as well as its deproteinization were achieved simultaneously by centrifugation of semen in a molecular filtration cone at $4{ }^{\circ} \mathrm{C}$ for $20 \mathrm{~min}$. Free $\mathrm{L}(-)$-carnitine determinations on the filtrate were made by a spectrophotometric method (Marquis \& Fritz, 1964; Soufir, Marson \& Jouannet, 1981).

Fructose determinations were carried out on the filtrate using a specific enzymic method (Bernt \& Bergmeyer, 1974).

\section{Results}

The PG concentrations in the semen of the various types of men are shown in Table 1. Values in normal and vasectomized men were similar except for that of 19-OH-PGE $(1+2)$ in vasectomized men which was significantly lower $(P<0.05$, Student's $t$ test $)$. The PG values in men with obstructive sterility were $10^{2}-10^{5}$ lower than normal values.

More detailed examination was carried out on 4 ejaculates split into 5 fractions (Table 2). A close relation existed between the pattern of 19-OH-PGE $(1+2), 19-\mathrm{OH}-\mathrm{PGF}-\alpha$ and PGF- $\alpha(1+2)$ 
Table 1. Prostaglandin concentrations $(\mu \mathrm{g} / \mathrm{ml})$ in human semen

\begin{tabular}{|c|c|c|c|c|c|c|}
\hline \multirow[b]{2}{*}{ Prostaglandins } & \multicolumn{2}{|r|}{ Normal men } & \multicolumn{2}{|r|}{ Vasectomized men } & \multicolumn{2}{|c|}{$\begin{array}{c}\text { Men with agenesia } \\
\text { of vas }\end{array}$} \\
\hline & $\begin{array}{l}\text { No. of } \\
\text { men }\end{array}$ & Mean \pm s.e.m. (range) & $\begin{array}{l}\text { No. of } \\
\text { men }\end{array}$ & Mean \pm s.e.m. (range) & $\begin{array}{c}\text { No. of } \\
\text { men }\end{array}$ & Range $\times 10^{-3}$ \\
\hline 19-OH-PGE- $(1+2)$ & 11 & $375 \pm 140(141-640)$ & 8 & $215 \pm 116(66-446)$ & 4 & $9-332$ \\
\hline 19-OH-PGF- $\alpha$ & 9 & $21 \pm 10(3-29)$ & 7 & $16 \pm 6(7-29)$ & 4 & $1-116$ \\
\hline PGE-2 & 11 & $14 \pm 11(1-34)$ & 8 & $11 \pm 6(2-51)$ & 4 & $0 \cdot 6-15$ \\
\hline PGE-1 & 11 & $7 \pm 6(1-16)$ & 8 & $9 \pm 16(0.4-50)$ & 4 & $0 \cdot 1-9$ \\
\hline PGF- $2 \alpha$ & 11 & $2 \pm 2(0.3 \pm 7.7)$ & 8 & $1.3 \pm 1.3(0 \cdot 1-4 \cdot 5)$ & 4 & $0.2-37$ \\
\hline PGF-1 $\alpha$ & 11 & $1 \pm 0.7(0.1-2.1)$ & 8 & $0.8 \pm 0.9(0.1-3.3)$ & 4 & $0 \cdot 2-20$ \\
\hline
\end{tabular}

Table 2. Prostaglandin ( 4 cases), fructose and carnitine ( 3 cases) concentrations in 5 fractions of the split ejaculate of normal men (mean \pm s.e.m., $\mu \mathrm{g} / \mathrm{ml}$ )

\begin{tabular}{ccccccc}
\hline Fraction & 19-OH-PGE-(1+2) & 19-OH-PGF- $\alpha$ & PGE- $(1+2)$ & PGF- $\alpha(1+2)$ & Fructose & Carnitine \\
\hline 1 & $139 \pm 52$ & $13 \pm 6$ & $29 \pm 13$ & $3 \cdot 5 \pm 2$ & $690 \pm 390$ & $5190 \pm 1870$ \\
2 & $210 \pm 72$ & $25 \pm 9$ & $34 \pm 10$ & $5 \cdot 0 \pm 3$ & $1500 \pm 930$ & $3160 \pm 2090$ \\
3 & $277 \pm 72$ & $34 \pm 9$ & $39 \pm 22$ & $7 \cdot 0 \pm 4$ & $1870 \pm 1410$ & $1450 \pm 860$ \\
4 & $298 \pm 91$ & $38 \pm 12$ & $40 \pm 21$ & $8 \cdot 0 \pm 5$ & $2350 \pm 1550$ & $1590 \pm 1470$ \\
5 & $347 \pm 107$ & $44 \pm 12$ & $38 \pm 17$ & $8 \cdot 0 \pm 4$ & $3010 \pm 1640$ & $680 \pm 600$ \\
\hline
\end{tabular}

and fructose, although the PGs appeared earlier in the ejaculate. L-Carnitine concentrations decreased as PG and fructose concentrations increased.

\section{Discussion}

The secretions in the semen of men with vas and seminal vesicle agenesia are of prostatic origin. The very low PG content in the semen of such men excludes a prostatic origin of seminal prostaglandins.

After vasectomy, semen is free from spermatozoa and epididymo-testicular secretions; it consists of products which originate in the seminal vesicles, the prostate and the part of vas that includes the ampulla. High PG concentrations in the semen of such men show that the PGs do not originate at the proximal part of the vas, the testis or the epididymis, and that the spermatozoa are not the source of seminal PGs. Spermatozoa are not capable of transforming labelled arachidonic acid (Schlegel, Rotermund, Farber \& Nieschlag, 1981). In the present study, in a split ejaculate, carnitine concentrations decrease as PG and fructose level increase. Carnitine originates predominantly in the epididymis (Soufir et al., 1981).

It is therefore suggested that the seminal vesicles are the source of the largest PG fraction in human semen, as shown by the parallelism between the PG and the fructose pattern. These results confirm previous hypotheses and observations (Eliasson, 1959; Conte et al., 1979).

The production of a small part of the seminal PGs, especially PGE-2, at another site (e.g. vas deferens ampulla for instance), cannot be excluded.

We thank Miss A. Pesty for technical assistance, and Mrs M. Berson and E. Pagis for secretarial assistance. This work was supported by a grant from D.G.R.S.T. 80.E.0805. 


\section{References}

Bernt, E. \& Bergmeyer, H.U. (1974) D-fructose. In Methods of Enzymatic Analysis, 2nd edn, vol. 3, pp. 1304-1307. Ed. H. U. Bergmeyer. Academic Press, New York.

Bygdeman, M. \& Eliasson R. (1969) Distribution of prostaglandins, fructose and acid phosphatase in human seminal plasma. Andrologia 1, 5-10.

Cenedella, R.J. (1975) Prostaglandins and male reproductive physiology. In Molecular Mechanisms of Gonadal Hormone Action, Vol. 1, pp. 325-358. Eds J. A. Thomas \& R. L. Singhal. Aylesbury.

Conte, D., Laguzzi, G., Gioveno, P., Dondero, F. \& Isidori, A. (1979) Relationship between seminal PGE and 19-OH-PGE and seminal fructose in man. Prostaglandins 17, 135-139.

Dray, F., Charbonnel, B. \& Maclouf, J. (1975) Radioimmunoassay and prostaglandins F- $\alpha, \mathrm{E}-1, \mathrm{E}-2$ in human plasma. Eur. J. Clin. Invest. 5, 311-318.

Dray, F., Gerozissis, K., Kouznetzova, B., Mamas, S., Pradelles, P. \& Trugnan, G. (1980) New approach to the RIA of prostaglandins and related compounds using iodinated tracers. Adv. Prostaglandin Thromboxane Res. 6, 167-180.

Eliasson, R. (1959) Studies on PG occurrence, formation and biological actions. Acta Physiol., Scand. 46, Suppl. 158, 1-73.

Eliasson, R. \& Lindholmer, G. (1976) Functions of male accessory genital organs. In Human Semen and Fertility Regulation in Men, pp. 44-50. Ed. E. S. E. Hafez. Mosby \& Co., St Louis.
Fuchs, A.R. \& Chantharaksri, U. (1976) Prostaglandins and male fertility. In Human Semen and Fertility Regulation in Men, pp. 187-197. Ed. E. S. E. Hafez. Mosby \& Co., St Louis.

Gerozissis, K. \& Dray, F. (1977) Prostaglandins in the isolated testicular capsule of immature and young adult rat. Prostaglandins 13, 777-783.

Gerozissis, K. \& Dray, F. (1981) Radioimmunoassay of prostaglandins in the semen of fertile men. J. Reprod. Fert. 61, 487-490.

Hamberg, M. (1976) Biosynthesis of prostaglandin E-1 by human seminal vesicles. Lipids 11, 249-250.

Maclouf, J., Pradel, M., Pradelles, P. \& Dray, F. (1976) ${ }^{125}$ I derivatives of prostaglandins. Biochim. Biophys. Acta 431, 139-146.

Marquis, R.N. \& Fritz, I.B. (1964) Enzymological determination of free carnitine concentrations in rat tissues. J. Lipid Res. 5, 184-187.

Schlegel, W., Rotermund, S., Farber, G. \& Nieschlag, E. (1981) The influence of prostaglandins on sperm motility. Prostaglandins 21, 87-99.

Soufir, J.C., Marson, J. \& Jouannet, P. (1981) Free L-carnitine in human seminal plasma. Int. J. Androl. 4, 388-397.

Taylor, R.L. \& Kelly, R.W. (1974) 19-Hydroxylated E prostaglandins as the major prostaglandins of human semen. Nature, Lond. 250, 665-667.

Templeton, A.A., Cooper, I. \& Kelly, R.W. (1978) Prostaglandin concentrations in the semen of fertile men. J. Reprod. Fert. 52, 147-150.

Received 11 September 1981 